
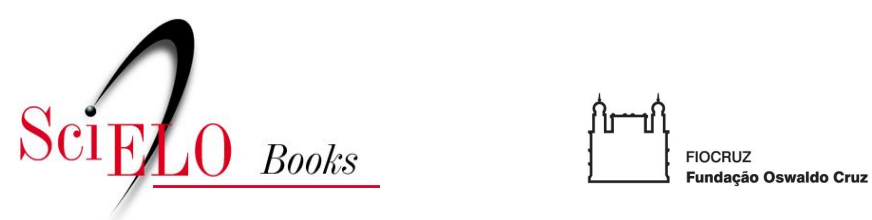

ipea

\title{
Determinantes sociais, econômicos e ambientais da saúde
}

\author{
Antonio Ivo de Carvalho
}

\section{SciELO Books / SciELO Livros / SciELO Libros}

CARVALHO, AI. Determinantes sociais, econômicos e ambientais da saúde. In FUNDAÇÃO OSWALDO CRUZ. A saúde no Brasil em 2030 - prospecção estratégica do sistema de saúde brasileiro: população e perfil sanitário [online]. Rio de Janeiro: Fiocruz/Ipea/Ministério da Saúde/Secretaria de Assuntos Estratégicos da Presidência da República, 2013. Vol. 2. pp. 19-38. ISBN 978-85-8110-016-6. Available from SciELO Books <http://books.scielo.org>.

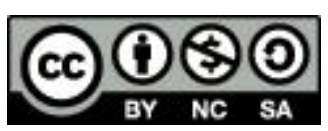

All the contents of this chapter, except where otherwise noted, is licensed under a Creative Commons Attribution-Non Commercial-ShareAlike 3.0 Unported.

Todo o conteúdo deste capítulo, exceto quando houver ressalva, é publicado sob a licença Creative Commons Atribuição Uso Não Comercial - Partilha nos Mesmos Termos 3.0 Não adaptada.

Todo el contenido de este capítulo, excepto donde se indique lo contrario, está bajo licencia de la licencia Creative Commons Reconocimento-NoComercial-CompartirIgual 3.0 Unported. 
Determinantes Sociais, Econômicos

e Ambientais da Saúde 


\section{DETERMINANTES SOCIAIS, ECONÔMICOS E AMBIENTAIS DA SAÚDE Antonio Ivo de Carvalho}

Embora seja há muito conhecido que a saúde-doença se produz e distribui na sociedade mediante fortes processos de determinação social, econômica, cultural, ambiental, política, etc., só recentemente este conceito vem sendo incorporado ao arcabouço conceitual e prático para a formulação de políticas e estratégias em direção à saúde. É, sobretudo a partir de 2003, com a criação da Comissão Global sobre Determinantes Sociais da Saúde, que se inicia um processo de sistematização do conhecimento disponível e de articulação, no plano mundial, de iniciativas e fomento de políticas inspiradas nesse referencial. De imediato isso representou um alargamento do campo da saúde e o fortalecimento de abordagens intersetoriais para as políticas e ações de saúde.

Na verdade, desde os anos 90, vem-se realizando Cúpulas Mundiais no âmbito das Nações Unidas, com grande participação dos países, sobre temas de relevância para a humanidade. Tais encontros refinaram e ampliaram o marco conceitual, recolheram experiências exitosas e produziram recomendações de políticas de enfrentamento dos determinantes sociais de saúde, sobretudo com vistas a diminuir as iniquidades sociais e em saúde.

As condições econômicas e sociais influenciam decisivamente as condições de saúde de pessoas e populações. A maior parte da carga das doenças assim como as iniquidades em saúde, que existem em todos os países - acontece por conta das condições em que as pessoas nascem, vivem, trabalham e envelhecem. Esse conjunto é denominado "determinantes sociais da saúde", um termo que resume os determinantes sociais, econômicos, políticos, culturais e ambientais da saúde.

Nem todos os determinantes são igualmente importantes. Os mais destacados são aqueles que geram estratificação social - os determinantes estruturais que refletem as condições de distribuição de riqueza, poder e prestígio nas sociedades, como a estrutura de classes sociais, a distribuição de renda, o preconceito com base em fatores como o gênero, a etnia ou deficiências e estruturas políticas e de governança que alimentam, ao invés de reduzir, iniquidades relativas ao poder econômico. Entre os mecanismos que geram e mantêm essa estratificação estão as estruturas de propriedade dos meios de produção e a distribuição de poder entre as 
classes sociais, e as correspondentes instituições de governança formais e informais; sistemas de educação, estruturas de mercado ligadas ao trabalho e aos produtos; sistemas financeiros, o nível de atenção dado a considerações distributivas no processo de formulação de políticas; e a extensão e a natureza de políticas redistributivas, de seguridade social e de proteção social. Esses mecanismos estruturais, que alteram o posicionamento social dos indivíduos, são a causa mais profunda das iniquidades em saúde. São essas diferenças que — com seu impacto sobre determinantes intermediários como as condições devida, circunstâncias psicossociais, fatores comportamentais e/ ou biológicos e o próprio sistema de saúde —dão forma às condições de saúde dos indivíduos.

Esse conceito abrangente de determinantes sociais da saúde, visualizado na Figura 1, foi adotado pela OMS em seu relatório "Diminuindo Diferenças: a prática das políticas sobre determinantes sociais da saúde", discutido na Conferência Mundial sobre Determinantes da Saúde, no Rio de Janeiro (OMS, 2011). Neste modelo, os determinantes estruturais compreendem a distribuição de renda, o preconceito baseado em valores relativos a gênero e etnia, e os determinantes intermediários configuram-se nas condições de vida, nos aspectos psicossociais, nos elementos comportamentais e/ ou biológicos e no próprio sistema de saúde.

Figura 01. Marco conceitual dos determinantes sociais da saúde

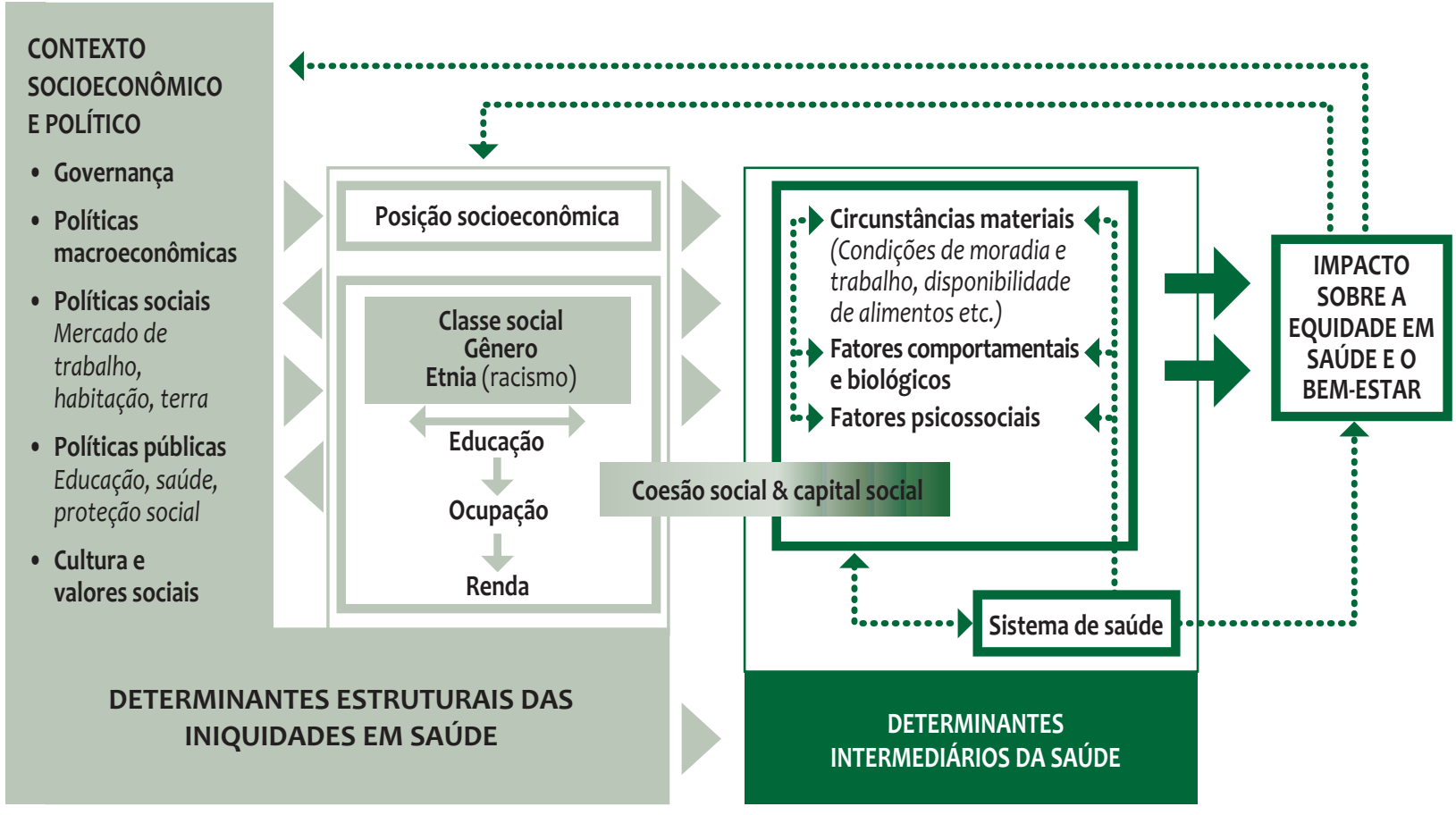

Fonte: SOLAR \& IRWIN, 2010. 
Para melhorar a situação da saúde e reduzir iniquidades, considerando essa abordagem dos determinantes sociais, é necessário que intervenções coordenadas e coerentes entre si sejam implementadas nos setores da sociedade que influenciam seus determinantes estruturais. Por sua vez, a boa saúde contribui para outras prioridades sociais como o bem-estar, a educação, a coesão social, a preservação do meio ambiente, o aumento da produtividade e o desenvolvimento econômico. Isso gera um "círculo virtuoso" no qual a saúde e os seus determinantes se retroalimentam e se beneficiam mutuamente.

Portanto, adotar a abordagem dos determinantes sociais significa compreender o valor que a saúde tem para a sociedade e admitir que ela depende de ações que, muitas vezes, não têm relação com o setor Saúde.

A abordagem dos determinantes sociais reconhece o fato de que as iniquidades em saúde não podem ser combatidas sem que as iniquidades sociais também o sejam. Para que a economia permaneça forte e a estabilidade social e a segurança global sejam mantidas, é essencial que ações coordenadas em prol da saúde sejam implementadas. Enfatizar os determinantes sociais significa, portanto, apoiar ações coerentes sobre algumas prioridades, tais como, por exemplo, a proteção social e as mudanças climáticas. Ademais, essa abordagem leva em consideração a desigualdade intergeracional, que vinha sendo ignorada, mas hoje é central para essas questões que desafiam as políticas públicas. As mudanças climáticas - um símbolo da degradação ambiental como um todo - ameaçam o bem-estar das gerações futuras. O aumento da incidência de doenças não transmissíveis e a perda de oportunidades econômicas e benefícios da previdência social que se observa em países de todos os níveis de renda já vêm causando iniquidades intergeracionais, reduzindo a expectativa de vida e causando insatisfações na população.

A saúde é um fator-chave para um amplo espectro de metas da sociedade. A abordagem dos determinantes sociais identifica a distribuição da saúde - medida pelo grau de desigualdade em saúde - como um importante indicador não só do nível de igualdade e justiça social existente numa sociedade, como também do seu funcionamento como um todo. Portanto, as iniquidades em saúde funcionam como um indicador claro do sucesso e do nível de coerência interna do conjunto de políticas de uma sociedade para uma série de setores. Sistemas de saúde que reduzem as iniquidades em saúde oferecendo um melhor desempenho e, assim, melhorando rapidamente as condições de saúde de grupos carentes acabarão por oferecer um desempenho mais eficiente também para todos os estratos sociais.

Convidados pela Organização Mundial da Saúde (OMS), chefes de governo, ministros e representantes dos governos se reuniram em outubro de 2011, no Rio de Janeiro, para expressar sua determinação de promover a equidade social e em saúde por meio de ações sobre os determinantes sociais da saúde e do bem-estar, implementadas 
mediante uma ampla abordagem intersetorial. O documento "Declaração Política do Rio sobre Determinantes Sociais da Saúde" (OMS, 2011) sintetiza os compromissos então estabelecidos:

- reafirmaram que a equidade em saúde é uma responsabilidade compartilhada e demanda o engajamento de todos os setores governamentais, de todos os segmentos da sociedade e de todos os membros da comunidade internacional em uma ação global de "todos pela equidade" e "saúde para todos";

- sublinharam o valor essencial da equidade em saúde constante nos princípios e disposições contidos na Constituição da OMS assinada em 1946 e na Declaração de Alma Ata de 1978, e na série de conferências internacionais sobre promoção da saúde;

- reconheceram que "o gozo do mais alto nível de saúde que se possa atingir constitui um dos direitos fundamentais de todo ser humano, sem distinção de raça, religião, credo político e condição econômica ou social";

- declararam que os governos têm uma responsabilidade pela saúde de seus povos, a qual só pode ser cumprida por meio da promoção de medidas sociais e sanitárias adequadas, e que os esforços nacionais precisam ser apoiados por um ambiente internacional favorável;

- reiteraram que as desigualdades em cada país e entre os países são política, econômica e socialmente inaceitáveis - além de injustas e, em grande parte, evitáveis - e que a promoção da equidade em saúde é fundamental ao desenvolvimento sustentável e à melhoria da qualidade de vida e bem-estar para todos, o que, por sua vez, contribui para a paz e a segurança.

Assim, a lógica dos determinantes sociais da saúde coloca três imperativos. Primeiro, reduzir as iniquidades em saúde é um imperativo moral. Segundo, também é fundamental melhorar a saúde e ampliar o bem-estar, promover o desenvolvimento e, de forma geral, alcançar as metas de saúde. Terceiro, acima de tudo, para que uma série de metas prioritárias da sociedade - que dependem de uma distribuição igualitária da saúde — sejam alcançadas, é preciso realizar ações sobre os determinantes sociais.

O escopo das recentes crises financeira, alimentar, ambiental e de saúde pública, entre outras, que o mundo vem enfrentando desde 2008 deixaram ainda mais claro que a interconectividade do mundo moderno faz com que os países não possam enfrentar esses desafios sozinhos ou por meio de ações sobre setores isolados. 
Ao invés disso, é preciso realizar esforços consistentes em todos os níveis, do local ao global. Essas emergências revelaram falhas de regulação e uma ênfase excessiva em indicadores superficiais de crescimento econômico, demonstrando a necessidade de ações coordenadas e de um Estado forte.

Abrindo espaço real para o debate de políticas e objetivos, as crises criaram condições sem precedentes para a adoção de abordagens ligadas aos determinantes sociais da saúde. Ao mesmo tempo e paradoxalmente, essas crises intensificaram, em alguns países, o desafio político que é implementar uma abordagem ligada aos determinantes sociais, especialmente no que tange a redistribuição, direitos e regulação. Em resposta à redução do espaço fiscal, foram demandadas reduções em serviços sociais que influenciam fortemente os determinantes sociais. Há o risco de que essa tendência faça com que erros do passado - que produziram impactos negativos sérios e extensos sobre a equidade em saúde — se repitam. É preciso aprender com os países que mantiveram ou até mesmo aumentaram os gastos nos principais determinantes sociais em tempos de crise.

\section{1 | TRÊS PRINCÍPIOS DE AÇÃO}

O relatório da OMS confirmado na Conferência Mundial sobre Determinantes da Saúde, ocorrida no Rio de Janeiro, reafirmou os três princípios de ação:

1. Melhorar as condições de vida cotidianas — as circunstâncias em que as pessoas nascem, crescem, vivem, trabalham e envelhecem.

2. Abordar a distribuição desigual de poder, dinheiro e recursos - os motores estruturais das condições de vida referidas - nos níveis global, nacionais e locais.

3. Quantificar o problema, avaliar a ação, alargar a base de conhecimento, desenvolver um corpo de recursos humanos formado sobre os determinantes sociais da saúde e promover a consciência pública sobre o tema.

\subsection{Melhorar as condições de vida quotidianas - as circunstâncias em que as pessoas nascem, crescem, vivem, trabalham e envelhecem}

As desigualdades na organização da sociedade implicam que a liberdade para gozar de uma vida próspera e de boa saúde esteja distribuída de forma desigual 
dentro e entre sociedades. Essa desigualdade pode ser constatada nas condições vigentes na primeira infância e idade escolar, na natureza das condições laborais e de emprego, nas características físicas do ambiente de trabalho e na qualidade do ambiente natural em que as pessoas habitam. Do mesmo modo, a estratificação social determina o acesso e uso diferenciado de cuidados de saúde, com consequências para a promoção desigual de saúde e bem-estar, prevenção e recuperação de doenças e sobrevivência.

O Desenvolvimento na Primeira Infância (DPI) tem influência determinante nas possibilidades subsequentes de vida e saúde, através do desenvolvimento de conhecimentos, da educação e oportunidades profissionais. De forma direta, a primeira infância é afetada pelos riscos de obesidade, má nutrição, transtornos mentais, doenças cardiovasculares e criminalidade.

As crianças precisam de ambientes seguros, saudáveis, acolhedores, educativos e dinâmicos em que viver. Os programas de educação pré-escolar e as escolas, como parte do ambiente alargado que contribui para o seu desenvolvimento, podem ter um papel vital na construção das capacidades das crianças.

Para tanto é necessário o compromisso e implementação de uma abordagem abrangente da infância, baseada nos programas de sobrevivência infantil existentes, que alargue a intervenção na infância ao desenvolvimento social e emocional e linguístico e cognitivo e expanda a prestação de serviços e o âmbito da educação para incluir os princípios do desenvolvimento na primeira infância (físico, social e emocional, linguístico e cognitivo).

O local onde as pessoas vivem também afeta a sua saúde e possibilidade de gozar de uma vida próspera. Abrigo, habitação de qualidade, água limpa e condições sanitárias são direitos humanos e necessidades básicas para uma vida saudável.

O modelo corrente de urbanização coloca desafios significativos, particularmente os relacionados com as alterações climáticas. Atualmente, as emissões de gases de efeito de estufa são determinadas principalmente pelos padrões de consumo de cidades do mundo desenvolvido. A interferência e esgotamento dos sistemas climáticos e a tarefa de redução das desigualdades na saúde a nível global estão estreitamente relacionados.

São essenciais, para a igualdade na saúde, comunidades e vizinhanças que assegurem o acesso a bens básicos, que sejam socialmente coesas, concebidas para promover bem-estar físico e psicológico e que protejam o ambiente natural. É preciso colocar a saúde e a igualdade na saúde no centro das atenções da administração e do planejamento urbano, garantindo a disponibilidade de habitação de custo suportável, investindo na requalificação de bairros degradados, incluindo como prioridade o abastecimento de água e condições de saneamento, eletricidade e pavimentação 
das vias de comunicação para todos os lares, independentemente da sua capacidade financeira. E assegurar que o planejamento urbano promova comportamentos equitativos saudáveis e seguros, mediante: investimento em transportes ativos; planejamento do mercado de consumo de forma a controlar o acesso a produtos alimentares insalubres ou menos saudáveis; regulamentos de controle e planejamento ambiental de qualidade, inclusive com a restrição do número de postos de venda de bebidas alcoólicas.

Do mesmo modo, é necessário promover a igualdade na saúde entre zonas rurais e urbanas mediante o investimento sustentado no desenvolvimento rural, abordando-se as políticas e processos de exclusão que conduzem à pobreza rural, à ausência de propriedade e à migração.

As condições de emprego e trabalho têm efeitos dramáticos sobre a igualdade na saúde. Quando boas, podem assegurar estabilidade financeira, estatuto social, desenvolvimento pessoal, relações sociais, autoestima e proteção contra riscos físicos e psicossociais.

Na área do trabalho se desenvolvem muitas das influências importantes sobre a saúde, o que inclui tanto as condições de seu exercício como a natureza do trabalho em si. Uma força de trabalho flexível é entendida como uma vantagem para a competitividade econômica, mas traz consigo efeitos sobre a saúde. Condições laborais adversas podem expor os indivíduos a uma série de riscos para a sua saúde física e tendem a se apresentar em profissões de baixo estatuto.

Por meio da garantia de emprego justo e condições de trabalho dignas, governos, empregadores e trabalhadores podem contribuir para a erradicação da pobreza, minimizar as desigualdades sociais, reduzir a exposição a riscos físicos e sociais e melhorar as oportunidades para a saúde e o bem-estar.

Todos os indivíduos precisam de proteção social ao longo de todo o ciclo de vida, enquanto crianças, durante a sua vida ativa e em idade avançada. Também necessitam de proteção caso sofram eventos específicos, tais como doença, incapacidade e perda de rendimento ou trabalho. A pobreza infantil e a transmissão da pobreza de geração em geração são obstáculos relevantes à melhoria da saúde da população e à redução da desigualdade na saúde.

Os sistemas de proteção social redistributivos, em combinação com a capacidade das pessoas para levar uma vida próspera no mercado de trabalho, influenciam os níveis de pobreza. Os sistemas generosos de proteção social universal estão associados com uma melhor saúde da população, incluindo menores índices de mortalidade excessiva entre os idosos e menores taxas de mortalidade nos grupos desfavorecidos. 
O alargamento da proteção social a toda a população é um grande passo rumo à concretização da igualdade na saúde no período de uma geração. Isso inclui o alargamento da proteção social a todos os indivíduos em situação laboral precária, incluindo emprego informal e trabalho doméstico ou de prestação de cuidados.

A redução das desigualdades no período de uma geração implica a implementação de sistemas que permitam níveis saudáveis de condições de vida, abaixo dos quais ninguém deveria viver por razões que transcendam ao seu controle. Os programas de proteção social podem ser instrumentais na concretização de metas de desenvolvimento, em vez de serem dependentes da realização desses objetivos - podem ser meios eficientes para reduzir a pobreza, dos quais as economias locais podem se beneficiar.

O acesso e usufruto de cuidados de saúde são vitais para uma saúde equitativa e de qualidade. O sistema de cuidados de saúde é, em si mesmo, um determinante social da saúde, influenciado e influente do efeito de outros determinantes sociais. Gênero, educação, profissão, rendimento, origem étnica e local de residência estão intimamente ligados ao acesso, à experiência e aos benefícios dos cuidados de saúde. Cabe ao setor Saúde supervisionar e interagir com todos os ramos da sociedade para assegurar que as políticas e ações em outros setores melhorem a igualdade na saúde.

\section{2 | Abordar a distribuição desigual de poder, dinheiro e recursos}

Diferentes políticas de governo, dependendo da sua natureza, podem melhorar ou degradar a saúde e a equidade na saúde. Políticas públicas de qualidade podem produzir benefícios na saúde de forma imediata e em longo prazo.

A coerência política é crucial, pois implica que as políticas de diferentes órgãos governamentais se complementem, em vez de se contradizerem, relativamente à produção de riqueza e à igualdade na saúde. A ação intersetorial para a saúde desenvolvimento de políticas e ações coordenadas entre setores relacionados e externos à saúde - pode ser uma estratégia-chave para se atingir esses objetivos.

Transcender a ação governamental para envolver a sociedade civil e os setores privado e de voluntariado é um passo vital na ação para a igualdade na saúde. A inclusão crescente da participação da comunidade e da sociedade nos processos das políticas ajuda a assegurar decisões justas sobre os temas da igualdade na saúde. Tornar a saúde e a igualdade na saúde um valor partilhado entre diferentes setores constitui uma estratégia politicamente desafiante, porém necessária.

Urge colocar a responsabilidade pela ação sobre a saúde e a igualdade na saúde nos níveis governamentais mais elevados e assegurar a sua ponderação 
coerente por meio de todas as políticas, avaliando o impacto destas e dos programas sobre a saúde e a igualdade na saúde, com vista à coerência plena em toda a atividade governativa.

É necessário, ainda, fortalecer o financiamento público e atribuir equitativamente os recursos governamentais à ação sobre os determinantes sociais da saúde.

A administração do setor público não substitui as responsabilidades e capacidades dos restantes agentes: a sociedade civil e o setor privado. Os agentes do setor privado são influentes e têm o poder necessário para contribuir em muito para a igualdade na saúde em nível global.

A saúde não é uma mercadoria transacionável no mercado; é uma questão de direitos e um dever do setor público. Como tal, os recursos para o setor devem ser equitativos e universais. A experiência demonstra que a comercialização de bens sociais vitais, tais como educação e cuidados de saúde, provoca desigualdades na saúde; aoferta desses bens sociais vitais tem de ser administrada pelo setor público, e não deixada a cargo dos mercados. Além disso, deve haver liderança no setor público para uma regulação real de produtos e das atividades e condições que degradem a saúde ou conduzam a desigualdades neste setor. O que significa que a avaliação competente e regular do impacto de todas as políticas implementadas e instrumentos de regulação do mercado sobre a igualdade na saúde deve ser institucionalizada nos níveis nacionais e internacional.

Para mudar esta situação, é necessário institucionalizar a consideração do impacto da saúde e da igualdade na saúde nos acordos econômicos e na elaboração de políticas, em âmbito tanto nível nacional como internacional, reforçando a representação dos agentes da saúde nas negociações sobre políticas nacionais e internacionais. E, ainda, reforçar o papel primário do Estado na prestação de serviços essenciais à saúde (tais como água potável e saneamento) e na regulamentação de bens e serviços com impacto notável na saúde (tais como o tabaco, álcool e alimentos).

Os desequilíbrios no poder, recursos, atribuições hierárquicas, normas e valores e a forma como as organizações estão estruturadas e os programas são conduzidos também se refletem nas desigualdades de gênero, prejudicando a saúde de milhões de meninas e mulheres. As desigualdades de gênero influenciam a saúde mediante, entre outras formas, padrões de alimentação discriminatórios, violência contra as mulheres, déficit de poder de decisão e divisões injustas de trabalho, lazer e possibilidades de melhoria de condições de vida.

É necessário abordar as desigualdades de gênero nas estruturas da sociedade - na legislação e na sua aplicação, na forma como as organizações são 
geridas e como as intervenções são concebidas e nos métodos de avaliação de desempenho econômico do país. Isso significa criar e fazer cumprir legislação que promova a igualdade de gênero e torne ilegal a discriminação por questões de sexo, bem como incluir nas finanças nacionais a contribuição econômica advinda do trabalho doméstico, prestação de cuidados e trabalho voluntário.

Qualquer esforço sério para a redução das desigualdades na saúde envolve a alteração da distribuição do poder na sociedade, capacitando os indivíduos para representar de forma firme e eficaz as suas necessidades e interesses e, dessa forma, desafiar e modificar a distribuição injusta e diferente dos recursos sociais (as condições para a saúde) a que todos os cidadãos têm direito e aspiram.

A inclusão, atuação e controle são importantes para o desenvolvimento social, saúde e bem-estar, e a restrição da participação resulta na privação das capacidades humanas, abrindo caminho a desigualdades, por exemplo, na educação, no emprego e no acesso aos avanços técnicos e biomédicos disponíveis.

A ação comunitária ou da sociedade civil sobre as desigualdades na saúde não pode ser separada da responsabilidade dos Estados em garantir um conjunto abrangente de direitos e da distribuição justa dos bens materiais e sociais essenciais por entre os diferentes grupos da população.

As alterações nas relações de poder podem se desenrolar em diversos níveis, desde a escala micro, dos indivíduos, agregados familiares ou comunidades, à macro das relações estruturais entre as instituições e agentes econômicos, sociais e políticos. A capacitação dos grupos sociais, seja por meio da sua representação na decisão de agendas e na elaboração de políticas, seja para a ação massificada, desde as bases até ao topo da hierarquia social, é crucial para a concretização de um conjunto abrangente de direitos e a distribuição justa dos bens materiais e sociais essenciais entre os grupos populacionais. A luta contra as injustiças com que se deparam os grupos mais desprivilegiados da sociedade e o processo de organização dessas pessoas faz com que emerjam lideranças locais e dá aos indivíduos um maior sentido de controle sobre as suas vidas e o seu futuro.

Para se alcançar essa meta é necessário capacitar todos os grupos da sociedade através da representação justa nos processos de decisão sobre o funcionamento da sociedade, particularmente em relação ao seu efeito na igualdade na saúde, e criar e manter um enquadramento socialmente inclusivo para a elaboração de políticas. Isso significa reforçar os sistemas políticos legais para a proteção dos direitos humanos, assegurar a identidade legal e apoiar as necessidades e reivindicações dos grupos marginalizados, especialmente as populações indígenas. Assim como permitir que a sociedade civil se organize e atue segundo padrões que promovam e concretizem os direitos políticos e sociais que afetam a igualdade na saúde. 


\subsection{Quantificar e compreender o problema e avaliar o impacto das ações}

A ação sobre os determinantes sociais da saúde será mais eficiente se os sistemas de informação, incluindo o registro de dados vitais e a monitorização de rotina das desigualdades na saúde e dos determinantes sociais da saúde, forem implementados e se houver mecanismos que garantam a compreensão e aplicação da informação para o desenvolvimento de políticas, sistemas e programas mais eficazes. A educação e a formação acerca dos determinantes sociais da saúde são absolutamente imperativas.

Para tanto, cabe assegurar que os sistemas de monitorização de rotina sobre a igualdade na saúde e os determinantes sociais da saúde sejam implementados em escalas local, nacional e internacional; investir na produção e compartilhamento de novas evidências sobre os modos como os determinantes sociais influenciam a saúde da população e a igualdade na saúde e sobre a eficácia das medidas para redução das desigualdades na saúde por meio da ação sobre os determinantes sociais; e fornecer informação aos agentes das políticas, intervenientes e profissionais sobre os determinantes sociais da saúde e investir na sensibilização do público em geral.

\section{2 | A QUESTÃO DOS DETERMINANTES E O BRASIL}

Com uma Constituição voltada para os aspectos sociais e uma economia que tem buscado, no período mais recente, um compromisso com a redistribuição da riqueza nacional a parcelas tradicionalmente menos favorecidas, não são pequenos os desafios que o Brasil deve enfrentar.

Neste último século, o país cresceu, as condições de vida melhoraram significativamente, incorporando novas parcelas da população aos benefícios do crescimento e do desenvolvimento tecnológico. No entanto, permanecem distorções quanto à equidade que devem ser equacionadas.

O coeficiente de Gini, indicador que mede a desigualdade, reduziu-se de 0,584 em 1981 para 0,543 em 2009, no Brasil. Essa queda pode ser explicada por melhorias na educação e pelo impacto dos vários programas de transferência de renda instituídos no país, nos últimos anos. Variações regionais persistem, como o coeficiente de 0,611 e 0,591 no Acre e na Paraíba, respectivamente, e o melhor posicionamento de outros estados como Santa Catarina $(0,460)$ e São Paulo $(0,489)$ (IPEA, 2011).

Em 1981, 12,7\% da renda nacional eram apropriados pelo estrato 1\% mais rico da população. Essa proporção se acentuou entre 1990 e 2001, com valores de 14\% e $13,9 \%$, respectivamente, para retornar a patamares inferiores em 2009, 12,1\%.Visto de 
outro ângulo, em 1981, os 50\% mais pobres apropriavam-se de 13\% da renda nacional, proporção que passou a 11\% em 1990, 12,6\% em 2001 e 15,5\% em 2009 (IPEA, 2011).

No tocante à linha da pobreza, definida segundo conceitos da Organização das Nações Unidas para Agricultura e Alimentação (FAO), houve significativa redução, de 35\%, do número de domicílios extremamente pobres e de 28,6\% entre os domicílios considerados pobres, no período entre 2005 e 2009. Em números absolutos, o Brasil contava com 20.600.000 domicílios extremamente pobres em 2005, passando a 13.400.000 em 2009 (IPEA, 2011). Essa queda demonstra, seguramente, efeito do Programa Bolsa Família.

O Programa Bolsa Família contava em 2009 com 12,4 milhões de famílias atendidas, com valor médio do benefício por família de R \$94,92. Avaliação de impacto do Programa Bolsa Família demonstra resultados no incremento da matrícula escolar, no acesso a serviços de saúde, na cobertura vacinal e no aumento ponderal das crianças beneficiárias (IPEA, 2011).

Ainda no campo da proteção social, os benefícios de prestação continuada atingiram, em 2009, 3.166.845 beneficiários, dos quais 1.541 .220 idosos e 1.625 .625 pessoas com deficiência. A renda mensal vitalícia atendeu a 322.397 pessoas no mesmo período, sendo 237.307 por invalidez e 85.090 por idade (IPEA, 2011).

Em 2002, 6,8\% domicílios não tinham esgotamento sanitário, enquanto em 2009 esta proporção passou a 3,5\%. A canalização interna de água atingia 87\% em 2001, evoluindo para 93\% em 2009 (IBGE, 2012).

Segundo a Pesquisa Nacional por Amostra de Domicílios (PNAD/IBGE), a cobertura previdenciária total atingiu em 2008 o patamar de 59,3\% da população economicamente ativa, valor mantido em 2009, significando um incremento de cerca de 10\% em relação a 2002 (53,8\%). A população sem carteira assinada no total de empregos passou de 16,7\% em 2002 para 13,5\% em 2009. A taxa de desemprego aberto em 2009 foi de 8,2\%. A renda média decorrente do trabalho, recebida mensalmente, ajustada em reais de 2008, foi de $\mathrm{R} \$ 615,00$ em 1992, R\$ 724,00 em 2001 e R\$ 849,00 em 2009 (IPEA, 2011).

No setor de Educação, o país tem assinalado vitórias. A taxa de frequência líquida à escola tem se mantido em um patamar constante para o ensino fundamental, entre 93\% e 95\%. Sessenta por cento da população de 4 a 6 anos de idade já frequentam a pré-escola. A frequência líquida ao ensino médio, por sua vez, era inferior a 40\% no início da década, ultrapassou esse patamar em 2003 e chegou em 2009 a 50,9\% (IPEA, 2011).

No biênio 2008-2009, pela primeira vez, o índice de analfabetismo aparece abaixo da casa dos 10\%. Desde 2004, a redução média tem sido de 0,35 ponto percentual ao ano. Em 2004, a taxa foi de 11,45\% e em 2009, de 9,7\%. É importante destacar a disparidade ainda elevada nos índices de analfabetismo nas áreas rurais, em relação a 
todas as demais categorias. Em 2009, o índice de analfabetismo na população urbana metropolitana foi de 4,37\%, contrastando com os índices apurados na população urbana não metropolitana e rural - 9,10\% e 22,75\%, respectivamente (IPEA, 2011).

As mulheres não ficaram de fora desse esforço em prol da equidade. Sua participação no mercado de trabalho aumentou, passando de 38,8\% em 2002 para 43,1\% em 2009. No entanto, a remuneração média das mulheres ainda representava apenas $71,8 \%$ da recebida pelos homens, provavelmente por conta das diferenças de qualidade entre os trabalhos de cada um desses grupos. Em valores absolutos, as mulheres recebiam $R \$ 1.124,00$, enquanto os homens percebiam $\mathrm{R} \$ 1.565,00$, em 2009 (IPEA, 2012).

Algumas das metas previstas para o bicentenário da República visam, sem dúvida, a manter esse crescimento e caminhar em direção à redução de iniquidades. Entre elas, destacam-se as diretamente relacionadas aos determinantes sociais na saúde (BRASIL, SAE, 2012):

- Crescer a 7\% ao ano; aumentar a taxa de investimento para 25\% do Produto Interno Bruto (PIB); tornar a tributação menos regressiva; reduzir a taxa de inflação para o nível médio dos países emergentes; alcançar a inclusão financeira de 100\% da população adulta; aumentar para ao menos 8\% e 19\% a participação das regiões Norte e Nordeste, respectivamente, no PIB.

- Erradicara extrema pobreza; acelerar a redução da desigualdade na distribuição de renda; garantir a segurança alimentar e o acesso à água a todos os brasileiros; garantir proteção social a todas as famílias em situação de vulnerabilidade.

- Reduzir o desmatamento ilegal a zero; reduzir em 50\% a emissão de gases de efeito estufa; tratar de forma ambientalmente adequada 100\% dos resíduos sólidos; aumentar a reciclagem dos materiais em 30\%; aumentar em 100\% o volume de esgoto tratado; garantir a implementação de, no mínimo, 30\% do bioma amazônico e de 10\% dos demais biomas e da zona costeira e marinha como unidades de conservação.

- Zerar o déficit habitacional brasileiro; urbanizar o universo de assentamentos precários; promover a regularização fundiária de metade do universo de domicílios informais; implantar corredores de transporte urbano em todas as cidades com mais de 300 mil habitantes, capitais e regiões metropolitanas; assegurar $100 \%$ de acesso a saneamento ambiental em todas as cidades. 
- Duplicar a produção agropecuária; aumentar os níveis de controle de sanidade; agregar valor aos produtos agropecuários; reduzir à metade a concentração fundiária; regularizar a propriedade da terra; dobrar a produção de alimentos; dobrar a renda da agricultura familiar; dominar as tecnologias de microeletrônica e de produção de fármacos.

- Reduzir à metade a informalidade no trabalho; reduzir à metade a rotatividade no emprego; elevar a escolaridade do trabalhador para 12 anos; qualificar toda a força de trabalho; desonerar a folha de salários sem perda de direitos do trabalhador; erradicar o trabalho infantil.

- Erradicar o analfabetismo; universalizar o atendimento escolar de 4 a 17 anos; ter metade da população em idade escolar em horário integral; atingir as metas de qualidade na educação de países desenvolvidos; interiorizar a rede federal de educação para todas as microrregiões; assegurar a formação profissional dos jovens; atingir a marca de dez milhões de universitários; universalizar o acesso aos bens e conteúdos culturais a todos os brasileiros.

- Garantir proteção integral a crianças e adolescentes contra toda forma de violência; erradicar o trabalho escravo; prevenir agravos contra idosos e fortalecer o convívio familiar.

- Atingir a igualdade salarial entre homens e mulheres; eliminar todas as formas de violência contra as mulheres; promover a saúde integral das mulheres e os direitos sexuais e reprodutivos.

- Atingir a igualdade salarial entre negros e brancos; eliminar o diferencial de mortalidade entre negros e brancos; triplicar o número de estudantes negros nas universidades.

Este é um processo de longo prazo, que requer investimento imediato, com alterações consideráveis nas políticas sociais e na ação política.

\section{3 | NO PLANO INTERNACIONAL}

Desde a Cúpula do Milênio realizada em 2000, e através de suas recomendações e compromissos - a Declaração do Milênio e os Objetivos de Desenvolvimento do Milênio (ODM), as Nações Unidas têm focado a atenção mundial, 
de maneira bem sucedida, na ação visando a erradicação da pobreza extrema em todas as suas formas, a redução da desigualdade de gênero, entre outros temas relacionados aos determinantes sociais da saúde. O período de 15 anos, previsto para o alcance dos ODM, se completará ao final de 2015.

O processo preparatório para a Cúpula prevista para 2015 tem mobilizado inéditos esforços para a avaliação prática e atualização conceitual das experiências internacionais e nacionais inspiradas nos ODM, mobilizando governos, sociedade e outros atores.

O evento político mais importante foi a realização, em junho de 2012, da Cúpula Mundial para o Desenvolvimento Sustentável (Rio + 20), que foi chamada para, como questão de urgência, aperfeiçoar o trabalho de erradicação da pobreza extrema e da fome, além de adotar para os novos objetivos a serem estabelecidos em 2015 o referencial do desenvolvimento sustentável como centro dos novos objetivos mundiais. O documento final dessa Cúpula (O Futuro que Queremos) remete à exigência de estabelecer até 2015 os novos Objetivos do Desenvolvimento Sustentável (ODS).

Para tanto foi lançado pela ONU um Grupo de Trabalho Aberto intergovernamental para as Metas do Desenvolvimento Sustentável, com o objetivo de fazer recomendações sobre o planejamento desses objetivos à Assembleia Geral da ONU.

Desde então, vem sendo estabelecida uma agenda de iniciativas e fóruns de debate no plano internacional, a cargo do Secretário-Geral da ONU, Ban KImoon, que devem confluir para a elaboração da Agenda Mundial de Desenvolvimento Sustentável Pós-2015. (ONU, 2013a). Entre essas estratégias contam-se o Painel de Alto Nível de Pessoas Eminentes e a Rede de Soluções para o Desenvolvimento Sustentável da ONU (SDSN), lançados em 2012 para mobilizar o conhecimento tecnológico e científico do mundo relacionados aos desafios do desenvolvimento sustentável, incluindo o desenho e implementação de uma agenda pós-2015 em desenvolvimento sustentável global. (ONU, 2013b). A SDSN tem tido consultas mundiais extensas com seu Conselho de Liderança e uma rede mais ampla de grupos temáticos sobre questõeschave do desenvolvimento sustentável. Como um órgão incluindo expertises científicas e operacionais na vasta gama de desafios para o desenvolvimento sustentável, o Conselho de Liderança tem explorado como seria uma agenda integrada, concisa, baseada na ciência e voltada à ação para o mundo. Este documento, preparado pelo Conselho de Liderança da SDSN, consolida as principais conclusões destas discussões e do trabalho emergente dos grupos temáticos da SDSN. Também integra o grande número de comentários recebidos sobre uma versão inicial durante as duas semanas de consulta pública.

A SDSN apoia totalmente a visão da Rio+20 sobre o desenvolvimento sustentável como um conceito holístico englobado pelas quatro dimensões da 
sociedade: desenvolvimento econômico (incluindo o fim da extrema pobreza), inclusão social, sustentabilidade ambiental e boa governança, incluindo paz e segurança. As sociedades visam alcançar todas as quatro dimensões. Falhas em uma das áreas, tal como sustentabilidade ambiental ou igualdade de gênero, podem afetar o progresso das outras, tais como a erradicação da pobreza. Fraca governança e insegurança podem também facilmente afetar o progresso dos objetivos econômicos, sociais e ambientais.

O mundo tem mudado profundamente desde 2000, quando a Declaração do Milênio e os ODM foram adotados. Em particular, cinco mudanças tornarão o período seguinte, entre 2015 e 2030, diferente do período que se encerra em 2015: (i) a viabilidade de acabar com a pobreza extrema em todas as suas formas, (ii) um impacto humano drasticamente maior na Terra física, (iii) rápidas mudanças tecnológicas, (iv) crescente desigualdade, e (v) uma crescente difusão e complexidade de governança.

Os problemas atuais irão se expandir perigosamente sem uma radical e urgente mudança de curso. O mundo precisa de um arcabouço operacional para o desenvolvimento sustentável que possa mobilizar todos os atores chave (governos nacionais e locais, sociedade civil, empresas, ciência e academia) em todos os países.

O documento resultante da Rio+20 refere-se a três dimensões do desenvolvimento sustentável (econômica, social e ambiental) e boa governança, que às vezes é descrita como a fundação do desenvolvimento sustentável. Para simplificar, nos referimos aos quatro objetivos sociais como dimensões do desenvolvimento sustentável.

Um caminho de desenvolvimento sustentável se baseia em um arcabouço global de cooperação para abordar as quatro dimensões do desenvolvimento sustentável e deve ser baseado em quatro conceitos normativos relacionados: (i) o direito ao desenvolvimento para todos os países, (ii) direitos humanos e inclusão social, (iii) convergência de padrões de vida entre os países, e (iv) responsabilidades compartilhadas e oportunidades.

Para ser efetivo, um arcabouço compartilhado para o desenvolvimento sustentável deve mobilizar o mundo ao redor de um número limitado de prioridades e objetivos associados - provavelmente não mais de dez. O Conselho de Liderança da SDSN identificou os seguintes desafios prioritários, que são interconectados e onde cada um contribui às quatro dimensões do desenvolvimento sustentável:

- Acabar com a pobreza extrema, incluindo a fome: extinguir a pobreza extrema em todas as suas formas, incluindo a fome, desnutrição infantil, subnutrição e insegurança alimentar; e apoiar o países altamente vulneráveis (ODMs 1-7).

- Alcançar o desenvolvimento dentro dos limites planetários: todos os países têm direito a um desenvolvimento que 
respeite os limites planetários, garanta padrões de produção e consumo sustentáveis e ajude a estabilizar a população global até o meio do século.

- Assegurar aprendizagem efetiva para todas as crianças e jovens para a vida e para o sustento: todas as crianças, meninos e meninas, devem completar programas de desenvolvimento da primeira infância que sejam acessíveis e de alta qualidade, educação primária e secundária para prepará-los para os desafios da vida moderna e meios de vida decentes. Todos os jovens e adultos devem ter acesso a aprendizado contínuo, por toda a vida, para adquirir alfabetização funcional, aritmética e habilidades para ganhar seu sustento através de trabalhos decentes ou trabalhos autônomos.

- Alcançarigualdadedegênero,inclusãosocialedesenvolvimento humano para todos: garantir a igualdade de gênero, direitos humanos, estado de direito e acesso universal a serviços públicos. Reduzir a pobreza relativa e outras desigualdades que causam exclusão social. Prevenir e eliminar a violência e exploração, especialmente contra mulheres e crianças.

- Alcançar bem estar e saúde em todas as idades: alcançar cobertura universal de saúde em todos os estágios da vida, com particular ênfase em serviços primários de saúde, incluindo saúde reprodutiva, para garantir que todas as pessoas recebam serviços de saúde de qualidade sem passar por dificuldades financeiras. Todos os países devem promover políticas para ajudar indivíduos a fazerem escolhas saudáveis e sustentáveis em relação à dieta, atividade física e outras dimensões sociais e individuais da saúde.

- Aprimorar os sistemas de agricultura e elevar a prosperidade rural: melhorar práticas agrícolas, infraestrutura rural e acesso a recursos para produção de alimentos de forma a aumentar a produtividade agrícola, pecuária e pesqueira, aumentar a renda de pequenos produtores, reduzir os impactos ambientais, promover prosperidade rural e garantir resiliência às mudanças climáticas.

- Habilitar cidades inclusivas, produtivas e resilientes: tornar todas as cidades socialmente inclusivas, economicamente produtivas, ambientalmente sustentáveis, seguras e resilientes às mudanças climáticas e outros riscos. Desenvolver governança 
nas cidades que seja participativa, responsável e efetiva e que apoie transformações urbanas rápidas e igualitárias.

- Frear a mudança climática induzida pelo homem e assegurar energia limpa para todos: frear as emissões de gases do efeito estufa do setor de energia, indústria, agricultura, ambientes construídos e mudança no uso do solo a fim de garantir o pico de emissões globais de CO2 até 2020 e evitar os crescentes perigos das mudanças climáticas. Promover energia sustentável para todos.

- Assegurar serviços ecosistêmicos e biodiversidade, e garantir a gestão adequada da água e outros recursos naturais: biodiversidade e sistemas marinhos e terrestres de importância local, regional e global devem ser inventariados, gerenciados e monitorados para garantir a continuidade de sistemas de suporte à vida resilientes e adaptativos a fim de apoiar o desenvolvimento sustentável. Água e outros recursos devem ser manejados de forma sustentável e transparente, a fim de apoiar o desenvolvimento humano e econômico de forma inclusiva.

- Transformar a governança para o desenvolvimento sustentável: o setor público, empresas e outros stakeholder devem comprometer-se com a boa governança, incluindo transparência, responsabilidade, acesso a informação, participação, fim dos paraísos e sigilos fiscais e esforços para acabar com a corrupção. As regras internacionais governando finanças internacionais, comércio, comunicação corporativa, tecnologia e propriedade intelectual devem ser feitas de forma alinhada ao alcance dos ODS. Os financiamentos para redução da pobreza e bens públicos globais, incluindo esforços para evitar as mudanças climáticas, devem ser fortalecidos e baseados em um conjunto graduado de direitos e responsabilidades globais.

Estes dez desafios do desenvolvimento sustentável devem ser abordados nas escalas global, regional, nacional e local. Eles podem formar uma base plausível para construir os ODS de forma a desencadear soluções práticas que os governos, empresas e sociedade civil podem perseguir com alta prioridade. Alguns temas, como igualdade de gênero e direitos humanos atravessam todas as prioridades, porém, como exigem mobilização e liderança política, recomenda-se destacá-los em um objetivo específico.

ODS bem construídos irão ajudar o entendimento público a respeito dos complexos desafios para o desenvolvimento sustentável, inspirar ação pública e 
privada, promover pensamento integrado e incentivar a responsabilização. Os ODS serão complementares às ferramentas do direito internacional, tais como tratados e convenções globais, através da provisão de um quadro normativo. As crianças, em todos os lugares, deverão aprender sobre os ODS para ajuda-las a compreender os desafios que irão enfrentar quando adultos. Os ODS irão também mobilizar governos e o sistema internacional para fortalecer a mensuração e monitoramento para o desenvolvimento sustentável.

Os ODS podem também promover o pensamento integral entre as quatro dimensões do desenvolvimento sustentável e abandonar os debates fúteis que colocam uma dimensão contra a outra. Os desafios abordados pelos ODS propostos são inerentemente integrados, assim, com o desenvolvimento

\section{SAÚDE NA AGENDA DE DESENVOLVIMENTO PÓS-2015}

Uma das iniciativas de desdobramento da Rio+20 foi a realização de um encontro internacional que reuniu 50 dirigentes nacionais de saúde em Botswana, entre 4 e 6 de março de 2013. Foi chamado de Diálogo de Alto Nível sobre Saúde na Agenda de Desenvolvimento Pós-2015. Os convidados eram representantes de governos, da sociedade, da academia, do Painel de Pessoas Eminentes, de organizações internacionais, do setor privado e da juventude. Foi o resultado de seis meses de consultas sobre o assunto. (ONU, 2013c).

O relatório do encontro, pelas suas análises e conclusões, consagrou a saúde como centro do desenvolvimento sustentável.

Considerou saúde como beneficiária do desenvolvimento, como componente do desenvolvimento e um indicador-chave de um desenvolvimento baseado em direitos, centrado na população e equitativo.

Saúde é importante como um fim em si mesmo e como parte integrante do bem-estar humano, que inclui também as dimensões material, psicológica, social, educacional, laboral, ambiental, política e segurança. São dimensões interrelacionadas e interdependentes.

A nova agenda de desenvolvimento deve articular claramente e potencializar sinergias entre a saúde e os demais objetivos. Os objetivos devem ser estabelecidos de modo a haver coerência política e soluções compartilhadas entre os múltiplos setores, isto é, exigem um manejo de governo como um todo na gestão das ações intersetoriais. 
Saúde é componente e contribui com todas as áreas temáticas do desenvolvimento. Hoje já se propugna a recomendação "Saúde em todas as políticas".

\section{4 | REFERÊNCIAS BIBLIOGRÁFICAS}

BRASIL. SECRETARIA DE ASSUNTOS ESTRATÉGICOS (SAE). As metas do centenário. Disponível em: <www.sae.gov.br/brasil2022/?p=341>. Acesso em: 15 jan. 2012.

INSTITUTO BRASILEIRO DE GEOGRAFIA E ESTATÍSTICA (IBGE). Características dos domicílios in Séries Estatísticas \& Séries Históricas. Disponível em <http://seriesestatisticas.ibge.gov.br/ series.aspx?vcodigo=PD268\&sv=12\&t=esgotamento-sanitario>. Acesso em 17 dez. 2012

INSTITUTO BRASILEIRO DE GEOGRAFIA E ESTATÍSTICA (IBGE). Pesquisa Nacional por Amostra de Domicílios: acesso e utilização de serviços de saúde. Rio de Janeiro: IBGE, 2008.

INSTITUTO DE PESQUISA ECONÔMICA APLICADA (IPEA). Evolução da desigualdade de rendimento domiciliar per capita nos municípios brasileiros. Brasília: Ipea, 2011. Comunicado n. 112.

INSTITUTO DE PESQUISA ECONÔMICA APLICADA (IPEA). Políticas sociais: acompanhamento e análise. Ipea, Brasília, n. 19, 2011.

INSTITUTO DE PESQUISA ECONÔMICA APLICADA (IPEA). Base de dados social. Disponível em:<www.ipeadata.gov.br/.> Acesso em: 10 jan. 2012.

ORGANIZAÇÃO MUNDIAL DA SAÚDE (OMS). Declaração política do Rio sobre determinantes sociais da saúde. Rio de Janeiro, Brasil - 21 de outubro de 2011. Disponível em: <www.who.int/ sdhconference/declaration/Rio_political_declaration_portuguese.pdf.> Acesso em: 07 jan. 2012.

ORGANIZAÇÃO MUNDIAL DA SAÚDE (OMS). Diminuindo diferenças: a prática das políticas sobre determinantes sociais da saúde. Genebra: OMS, 2011. Disponível em: <www.who.int/ sdhconference/discussion_paper/Discussion_Paper_PT.pdf>. Acesso em: 07 jan. 2012.

ORGANIZAÇÃO MUNDIAL DA SAÚDE. Redução das desigualdades no período de uma geração. Igualdade na saúde através da ação sobre os seus determinantes sociais. Relatório Final da Comissão para os Determinantes Sociais da Saúde. Genebra: OMS, 2010,

SOLAR, O.; IRWIN, A. A conceptual framework for action on the social determinants of health. Social Determinants of Health Discussion Paper 2. Genebra: OMS, 2010. Disponível em: <http:// whqlibdoc.who.int/publications/2010/9789241500852_eng.pdf>. Acesso em: 17 jan. 2012.

ORGANIZAÇÃO DAS NAÇÕES UNIDAS (ONU). Uma Agenda de Ação para o Desenvolvimento Sustentável. Relatório da Sustenable Development Solutions Network, Junho de 2013. Disponível em www.post2015hlp.org. (2013a)

ORGANIZAÇÃO DAS NAÇÕES UNIDAS (ONU). A New Global Partnership: Eradicate Poverty and transform economies through sustainable development. The report of the High Level Panel of Eminent Persons on the Post-2015 Development Agenda, may 2013. Disponível em http://www. post2015hlp.org/wp-content/uploads/2013/05/UN-Report.pdf. (2013b)

ORGANIZAÇÃO DAS NAÇÕES UNIDAS (ONU). High Level Dialogue on Health in the Post-2015 Development Agenda. Meeting Report, March 13. Disponível em www.worldwewant2015.org. health. (2013c) 